\title{
A Feasibility Study for Determining the Sensible Heat Flux to and from Small Green Roofs
}

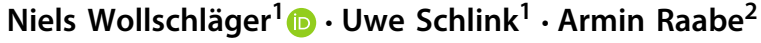 \\ Received: 2 September 2020 / Accepted: 25 June 2021 / Published online: 27 July 2021 \\ (c) The Author(s) 2021
}

\begin{abstract}
Eddy covariance is an established technique for registering sensible heat fluxes. However, this method is less adequate for smaller surfaces that cannot match the associated footprint. As an alternative technique, a recently constructed acoustic anemometer (Ly-ATOM) is tested, which operates horizontally at an extension of circa $1 \mathrm{~m}$ and a data-acquisition frequency of $1 \mathrm{~Hz}$. The Ly-ATOM device reproduces both the acoustic virtual temperature and the horizontal wind components registered by a three-dimensional sonic anemometer. As this Ly-ATOM device can be applied much closer to the ground compared with a sonic anemometer, the size of the related source area is significantly reduced (by a factor of 25). Two methods are used to retrieve the sensible heat flux from variance characteristics of temperature and the horizontal wind components recorded by the Ly-ATOM device: combining the flux-variancesimilarity and alternative-flux-variance methods for use in unstable and stable stratification, respectively, yields good results for the sonic measurements. Therefore, these methods can be applied to the Ly-ATOM device as well. In investigating the sensitivity to detect modified surface characteristics, specifically increased evapotranspiration and decreased surface albedo, the Ly-ATOM device proves to be superior to the sonic anemometer which is more vertically removed from the surface of interest.
\end{abstract}

Keywords Eddy-covariance method · Green roof · Flux-variance method · Sensible heat flux $\cdot$ Surface energy balance

\section{Introduction}

In recent years, sustainable development, especially of cities, has received increasing attention. Besides their potential for aesthetic improvement, green roofs are also considered to hold multiple environmental benefits (Berardi et al. 2014).

One of the benefits attributed to green roofs is the attenuation of urban heat stress. However, few studies evaluate the potential of green roofs to reduce the temperature at street level, with

\footnotetext{
Niels Wollschläger

niels.wollschlaeger@ufz.de

1 Helmholtz Centre for Environmental Research, Leipzig, Germany

2 University of Leipzig, Leipzig, Germany
} 
most using mesoscale models on an urban scale (Santamouris 2014). Overall, the results of such simulation studies regarding the cooling potential and temporal occurrence vary greatly (Rosenzweig et al. 2006; Chen et al. 2009; Ng et al. 2012). In this context, Morakinyo et al. (2017) found a distinct influence of the local climate and building height on this cooling potential. These inconsistencies in simulations on the urban scale are also accompanied by the still uncertain effect of green roofs on local micrometeorology. Green roofs are capable of reducing surface temperatures during summer months (Teemusk and Mander 2009; Morau et al. 2012; Bevilacqua et al. 2017), however, results concerning the cooling potential of green roofs on the ambient air temperature vary in terms of magnitude and temporal occurrence.

MacIvor et al. (2016) performed an experimental analysis above multiple small green roof modules with variations in substrate type, irrigation schedule, and plant community in Toronto. There, Sedum was particulary promoted for its cooling potential compared to other species (meadow mix of 15 grasses and scattered wildflowers) of up to $1.5 \mathrm{~K}$. Blanusa et al. (2013) compared different green roof species regarding leaf surface cooling, cooling of the substrate beneath the canopy layer, and air temperature in Reading, U.K. However, temperature differences between these species were only detected for the hottest summer days at a height of $0.3 \mathrm{~m}$. Stachys was found to outperform Sedum. Heusinger and Weber (2015) compared air temperature measurements at a height of $0.5 \mathrm{~m}$ of an extensive green roof to a bitumen roof and determined an air cooling effect of $0.7 \mathrm{~K}$ in Braunschweig, Germany. Speak et al. (2013) detected a decrease in monthly median air temperature of $1.06 \mathrm{~K}$ above an intensive green roof compared with a concrete roof at a height of $0.3 \mathrm{~m}$ in Manchester, U.K. Air temperature over the green roof was lower than over the concrete roof throughout the diurnal cycle, while higher daytime temperatures were found for a roof area with less maintenance resulting in damaged vegetation.

Green roofs with relatively abundant soil moisture have a comparable effect in reducing surface and near-surface temperatures to cool roofs with an albedo value of 0.7 ( $\mathrm{Li}$ et al. 2014). A study in Utrecht, Netherlands by Solcerova et al. (2016) compared temperatures at a height of $0.15 \mathrm{~m}$ across several green roof plots to a white gravel roof. There, a night-time cooling and daytime warming effect by the green roofs was observed, which resulted in a slight net warming of the air by the green roofs.

Overall, generalizations regarding green roof thermal performance are difficult since differences in air temperature are quite small and there are a variety of green roofs as well as reference roof designs. Jim and Peng (2012) showed a strong influence of the measurement height and background weather patterns on the green roof thermal performance. Furthermore, the thermal performance is influenced by the irrigation scenario and moisture availability (Heusinger et al. 2018; Zhang et al. 2020). This makes comparisons between studies even more difficult.

For a physically comprehensive assessment of the thermal effects of different types of green roofs, the surface energy balance should be considered (see, e.g., Foken 2017)

$$
\begin{aligned}
Q^{*} & =S W_{\downarrow}-S W_{\uparrow}-L W_{\uparrow}+L W_{\downarrow}, \\
& =S W_{\downarrow}-S W_{\downarrow} \alpha-L W_{\uparrow}+L W_{\downarrow}, \\
& =Q_{H}+Q_{E}+Q_{G}+Q_{R} .
\end{aligned}
$$

Solar radiation reaches the surface ( $S W_{\downarrow}$ flux density) whereby, depending on the surface albedo $\alpha$, shortwave radiation is reflected back into the atmosphere ( $S W_{\uparrow}$ flux density). Furthermore, the surface emits longwave radiation ( $L W_{\uparrow}$ flux density), according to the Stefan-Boltzmann law, but longwave radiation reaches the surface ( $L W_{\downarrow}$ flux density), too. These four components can be summarized as the net radiation $Q^{*}$. Usually, at noon, the 
net radiation is positive, whereby the surface gains more energy than it loses. This energy excess is transported away from the surface by several heat fluxes. The sensible heat flux $Q_{\mathrm{H}}$ causes heating of the lowermost hundreds of metres of the atmosphere and originates from the temperature difference between the surface and overlying air layers. The second turbulent heat flux is the latent heat flux $Q_{\mathrm{E}}$, which describes the water exchange processes (including evaporation, transpiration from plants, and condensation) between the surface and atmosphere. The ground heat flux $Q_{\mathrm{G}}$ quantifies the temperature exchange between surface and soil by heat conduction. Finally, the residual term in the surface energy balance $Q_{\mathrm{R}}$ covers undetected flux parts like advection terms, experimental limitations, or heat storage in both soil and roughness elements (Foken 2017).

Experimental studies dealing with the evaluation of heat fluxes of green roofs are rare, which can be attributed to the difficulties of appropriate measurement techniques. Considering surfaces with rather restricted spatial dimensions, $Q_{\mathrm{G}}$ and $Q_{\mathrm{E}}$ can be determined via the use of ground-heat-flux sensors, and lysimeters, respectively. However, the eddy-covariance (EC) method, which is the standard method, requires a three-dimensional acoustic anemometer (sonic) to determine the sensible heat flux $Q_{\mathrm{H}}$. The sonic requires a minimum height for applying the EC method, wherefore measurements may be impossible to perform inside the respective internal boundary layer (IBL) of the desired surface (Aubinet et al. 2012). The IBL describes a significantly developed disturbance layer near the surface, and causes several challenges for proper micrometeorological measurements. It originates from horizontal advection over discontinuities of the surface properties (Foken 2008). Due to the IBL, the exchanges of both mass and energy are also affected by the neighbouring area since the wind profile remains in balance with the previous surface (Pires et al. 2015). Therefore, measurements above the height of the IBL should be avoided; correct measurements are taken inside the IBL (Fig. 1). According to Foken (2008), in most cases the parametrization for the height of the IBL $\delta$ in m can be described by $\delta=0.3 \sqrt{s_{d}}$ (Raabe 1983), where $s_{d}$ denotes the run length $(\mathrm{m})$ to the next windward surface type.

In order to perform valid EC measurements above a green roof, Heusinger and Weber (2016) used a huge green roof with a size of $8600 \mathrm{~m}^{2}$ in Berlin, Germany as the study area. However, comparisons to similar green roof systems, including differences in plant choice, structure, etc. are difficult to perform since the second green roof may experience different meteorological conditions. Therefore, only generalized statements compared to conventional urban surfaces using the Bowen ratio $\beta=Q_{\mathrm{H}} / Q_{\mathrm{E}}$ could be made. Klein and Coffman (2015) compared EC measurements, which were conducted in Norman, Oklahoma, USA, above a conventional and a green roof with a size of $116.1 \mathrm{~m}^{2}$. Although a reduction in the magnitude of $Q_{\mathrm{H}}$ over the green roof was observed for days with generally high $Q_{\mathrm{H}}$ values, measurements within the corresponding IBL could not be guaranteed, leading to inaccuracies.

In the studies of Takebayashi and Moriyama (2012) and Heusinger and Weber (2015), multiple surfaces were investigated with respect to their impact on the urban climate by considering the sensible heat fluxes with the help of the Juerges equation, which is based on the difference between surface and air temperatures (Juerges 1924). While this method can be performed for surfaces with small dimensions, however, the surface temperature distribution of green roofs is not homogeneous, leading to inaccuracies in sensible heat flux estimations (Ayata et al. 2011).

Here, it is investigated whether valid acoustic measurements can be performed much closer to the ground compared to a standard sonic anemometer on a horizontal plane. In particular, the feasibility to detect sensible heat fluxes, based on temperature and wind fluctuations, with a small source area and inside the respective IBLs is examined. 


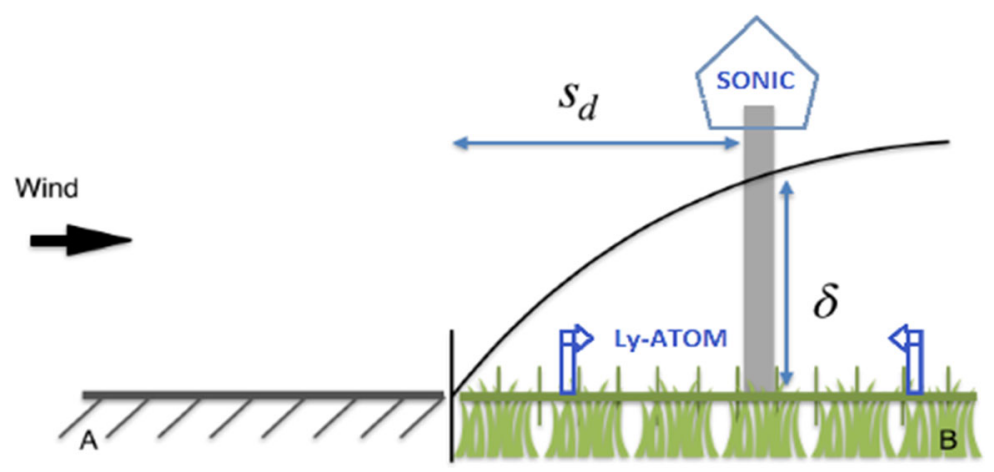

Fig. 1 Formation of an IBL: the surfaces A and B possess different surface roughness. The distance between surface change and measurement device (vertical grey bar) is $s_{d} ; \delta$ denotes the height of the IBL, which is represented by the curved black line. The measurements should be performed inside the IBL to avoid detecting the surface properties of surface A

\section{Theory}

\subsection{Derivation of Temperature and Velocity Based on Acoustic Measurements}

In a still atmosphere, acoustic wavefronts propagate at the Laplace speed of sound

$$
c_{\mathrm{L}}=\sqrt{\gamma_{\mathrm{d}} R_{\mathrm{d}} T_{\mathrm{av}}},
$$

with $\gamma_{\mathrm{d}}=1.4$ as the ratio of specific heat capacities at constant pressure $c_{\mathrm{P}}$ and constant volume $c_{\mathrm{V}}$, and the specific gas constant for dry air $R_{\mathrm{d}}=287.05 \mathrm{~m}^{2} \mathrm{~s}^{-2} \mathrm{~K}^{-1}$. In order to allow the use of the parameters for dry air, the acoustic virtual temperature $T_{\text {av }}=T(1+$ $0.513 q$ ) is used in (2), which takes the specific humidity $q$ and temperature $T$ into account. As a good approximation, the influence of the specific humidity may be neglected, since its contribution to the speed of sound is much lower compared with the air temperature (Barth and Raabe 2011).

The effective sound speed $c_{\text {eff }}$ depends on the travel times of acoustic signals $\tau$, which propagate along a ray path of length $d$. Besides the Laplace speed of sound, the effective sound speed $c_{\text {eff }}$ consists of a flow-dependent portion $v_{r}$, which denotes the velocity component in the direction of the sound propagation

$$
c_{\mathrm{eff}}=\frac{d}{\tau}=c_{\mathrm{L}}+v_{r}
$$

The temperature and the velocity component along a certain path can be separated by acoustic measurements in opposite directions and by applying the reciprocal method. Therefore, the Laplace speed of sound, which is temperature dependent, can be obtained by eliminating the dependence on the velocity component via adding the effective sound speeds in the forward direction $\left(c_{\mathrm{eff}, 1}\right)$ and backward direction $\left(c_{\mathrm{eff}, 2}\right)$ (Barth et al. 2013) by

$$
c_{\mathrm{L}}=\frac{c_{\mathrm{eff}, 1}+c_{\mathrm{eff}, 2}}{2}=\frac{d}{2}\left(\frac{1}{\tau_{1}}+\frac{1}{\tau_{2}}\right) .
$$

Afterwards, the acoustic virtual temperature can be derived from the definition of the Laplace speed of sound (2). In order to obtain the velocity component $v_{\mathrm{r}}$, the influence of the temperature needs to be eliminated by subtracting the effective sound speeds measured in the 
forward and backward directions by

$$
v_{\mathrm{r}}=\frac{c_{\mathrm{eff}, 1}-c_{\mathrm{eff}, 2}}{2}=\frac{d}{2}\left(\frac{1}{\tau_{1}}-\frac{1}{\tau_{2}}\right) .
$$

Hence, acoustic travel-time measurements enable the detection of the line-averaged temperature and the velocity components along a sound ray path.

\subsection{Eddy-Covariance Method}

The EC method is the only micrometeorological method that allows direct measurements of sensible and latent heat fluxes (Järvi et al. 2018). It is based on the assumption of horizontal homogeneity and that all transport processes of heat and moisture between the atmosphere and the ground-proximate layer take place only through turbulent mixing (Foken 2008; Zhao et al. 2010).

With the help of the covariance of temperature and the vertical velocity component $\overline{w^{\prime} T^{\prime}}$, the sensible heat flux can be calculated as

$$
Q_{\mathrm{H}-\mathrm{EC}}=\rho c_{\mathrm{P}} \overline{w^{\prime} T^{\prime}},
$$

where $\rho$ represents the air density, and $c_{\mathrm{P}}=1005 \mathrm{~J} \mathrm{~kg}^{-1} \mathrm{~K}^{-1}$.

For the determination of the heat fluxes with the EC method, small fluctuations need to be measured. Therefore, the quantities of interest must be measured with high temporal resolution, which is usually realized via the use of a sonic anemometer. According to Aubinet et al. (2012), an upwind fetch of the order of 100 times the measurement height is recommended.

\subsection{Flux-Variance-Similarity Method}

Another method for estimating the sensible heat fluxes is the flux-variance-similarity (FVS) method, which is based on Monin-Obukhov similarity theory (MOST). For an unstable atmospheric surface layer over a homogeneous and flat surface, the dimensionless (normalized) standard deviation $\sigma$ of a scalar quantity $X$ can be expressed as a function of the MoninObukhov stability parameter $\zeta$ (Tillman 1972; Cava et al. 2008) by

$$
\frac{\sigma_{X}}{X_{*}}=f_{X}(-\zeta)
$$

where $X_{*}=\overline{w^{\prime} X^{\prime}} / u_{*}$ is a scalar scale defined by the turbulent flux of the scalar $\overline{w^{\prime} X^{\prime}}$ and the friction velocity $u_{*}$. The Monin-Obukhov stability parameter $\zeta=z / L$ is given as the ratio of the measurement height $z$ and the Obukhov length $L$, which is defined as $L=-T u_{*}^{3} / \kappa g \overline{w^{\prime} T^{\prime}}$ with the von Kármán constant $\kappa=0.4$ and the acceleration due to gravity $g$.

The following characteristics of the function $f_{X}(-\zeta)(7)$ can be assumed (Tillman 1972; Wesson et al. 2001; Cava et al. 2008)

1. Neutral case: $-\zeta$ converges to zero and $f_{X}(-\zeta)$ approaches a constant.

2. Free convection limit: $-\zeta \rightarrow \infty$ and $\sigma_{x} / X_{*}$ should become independent of $u_{*}$

In the case of the sensible heat flux, the variable $X_{*}$ is replaced by the characteristic temperature scale $\left(T_{*}=-\overline{w^{\prime} T^{\prime}} / u_{*}\right)$. Taking both criteria into account, (7) yields

$$
-\frac{\sigma_{T}}{T_{*}}=C_{1}\left(C_{2}-\zeta\right)^{-1 / 3},
$$


with the similarity constants $C_{1}$ and $C_{2}$. Inserting the definitions of both $T_{*}$ and $Q_{H}(6)$ leads to

$$
\frac{\sigma_{T}}{C_{1}}\left(C_{2}-\zeta\right)^{1 / 3}=\frac{Q_{\mathrm{H}}}{\rho c_{\mathrm{P}} u_{*}} .
$$

Substituting for $u_{*}$ from the definition of $L$ and rearranging gives the following expression for the sensible heat flux, which is valid for the entire unstable range (Tillman 1972)

$$
Q_{\mathrm{H}-\mathrm{FV}}=\rho c_{\mathrm{P}}\left(\frac{\sigma_{T}}{C_{1}}\right)^{3 / 2}\left(\frac{\kappa g z}{T} \frac{C_{2}-\zeta}{-\zeta}\right)^{1 / 2} .
$$

In the case of free-convection conditions, (8) can be simplified according to Wyngaard et al. (1971) and Cava et al. (2008) as

$$
-\frac{\sigma_{T}}{T_{*}}=C_{1}(-\zeta)^{-1 / 3}
$$

which yields the following expression for the sensible heat flux

$$
Q_{\mathrm{H}-\mathrm{FV}}=\rho c_{\mathrm{P}}\left(\frac{\sigma_{T}}{C_{1}}\right)^{3 / 2}\left(\frac{\kappa g z}{T}\right)^{1 / 2} .
$$

Thus, for free convection conditions, the FVS method requires only high-frequency $(2-10 \mathrm{~Hz})$ measurements of air temperature at a single height (Ullah et al. 2019). However, the FVS method applies only to unstable atmospheric stratification $(-\zeta>0)$ and is not able to predict negative sensible heat fluxes since $\sigma_{T} \geq 0$. Thus, most studies when applying the FVS method, like Zhao et al. (2010), Wang et al. (2013), and Ullah et al. (2019), did not consider $Q_{\mathrm{H}}$ during night-time stable conditions.

\subsection{Alternative-Flux-Variance Method}

Based on the MOST relationships for temperature and the streamwise velocity component, an alternative-flux-variance (AFV) method for the estimation of the sensible heat flux $Q_{\mathrm{H}-\mathrm{AFV}}$ during stable conditions $(\zeta>0)$ is (De Bruin and Hartogensis 2005)

$$
\begin{aligned}
& \frac{\sigma_{u}}{u_{*}}=f_{u}(-\zeta) \approx C_{u}(-\zeta)^{m}, \\
& \frac{\sigma_{T}}{T_{*}}=f_{T}(-\zeta) \approx C_{T}(-\zeta)^{m},
\end{aligned}
$$

in which the exponent $m$ describes the influence of the magnitude of $\zeta$ for stable stratification. Using the definition of $T_{*}$, rearranging (14), and inserting (13) leads to

$$
\begin{aligned}
\overline{w^{\prime} T^{\prime}} & =-u_{*} \frac{\sigma_{T}}{C_{T}(-\zeta)^{m}} \\
& =-\frac{\sigma_{T}}{C_{T}(-\zeta)^{m}} \frac{\sigma_{u}}{C_{u}(-\zeta)^{m}} .
\end{aligned}
$$

According to Wesson et al. (2001) and Babić et al. (2016), an exponent of $m \approx 0$ for stable stratification can be assumed. Thus, the sensible heat flux can be calculated for stable conditions as

$$
\begin{aligned}
Q_{\mathrm{H}-\mathrm{EC}}=\rho c_{\mathrm{P}} \overline{w^{\prime} T^{\prime}} & =-\rho c_{\mathrm{P}} T_{*} u_{*} \\
& =-\rho c_{\mathrm{P}} \frac{\sigma_{u} \sigma_{T}}{C_{u} C_{T}}=Q_{\mathrm{H}-\mathrm{AFV}} .
\end{aligned}
$$



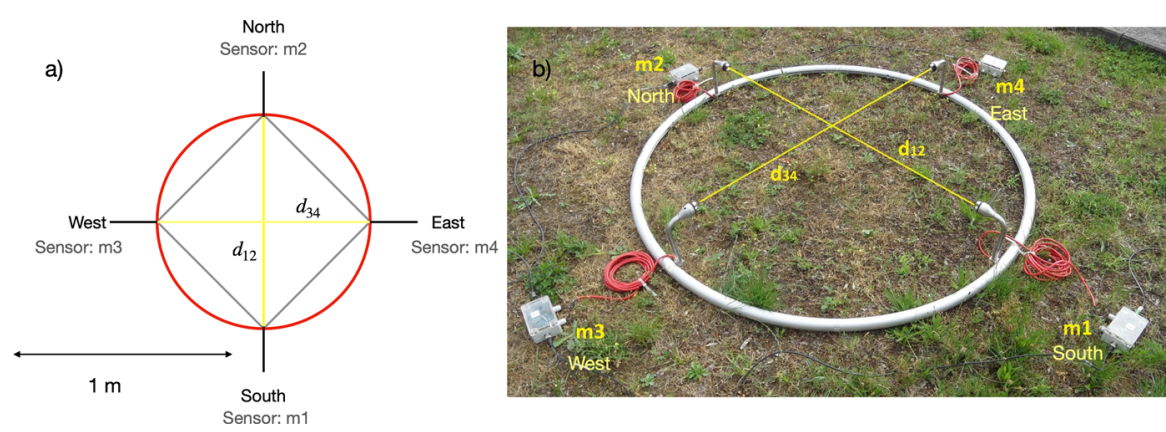

Fig. 2 Sensor arrangement of the Ly-ATOM set-up. The acoustic sensors are mounted on a metallic ring at a height of $0.25 \mathrm{~m}$ and aligned with the cardinal points. The considerations of this study are based on acoustic travel times of the sound ray paths $d_{1-2}$ and $d_{3-4}$ (yellow lines in panel a). Acoustic travel times of the outer sound ray paths (grey lines in panel a) were also available but are not considered here

In Sect. 3.3, the correction coefficients $r_{\text {corr }}=1 /\left(C_{u} C_{T}\right)$ are determined. Furthermore, the validity of the assumption $m=0$ is examined.

\section{Measurements and Methods}

\subsection{Measurement Site}

A measurement campaign in the garden of the Leipzig Institute for Meteorology (LIM), which is close to the city centre, was carried out from 23 June 2019 to 1 July 2019. The data analysis was performed in UTC, which is $2 \mathrm{~h}$ earlier than local time (Central European Summer Time).

An acoustic ultrasonic anemometer (USA-1, METEK, Elmshorn, Germany), which is shortened to sonic here, was used to determine the three velocity components and the temperature at a height of $2.3 \mathrm{~m}$ and at a sampling frequency of $10 \mathrm{~Hz}$.

For the detection of micrometeorological quantities and the representation of the energy fluxes between the surface and the atmosphere, four acoustic sensors at a height of $0.25 \mathrm{~m}$ were equidistantly attached on a metallic ring. The distance between the two opposing sensors, each consisting of a combination of transmitter and receiver-type ultrasonic sensors (A-18P20, EKULIT, Ostfildern, Germany), was about $1.3 \mathrm{~m}$. This device, which is depicted in Fig. 2, is called Ly-ATOM in the following, since it was originally designed to enable acoustic tomography measurements above lysimeters (Raabe et al. 2012). Initially, the LyATOM set-up was placed on a concrete surface. On 25 June 2019 at 0700 UTC, a rolled sod was laid, and the surface was modified by irrigation and a dark foil (see Table 1). It was ensured that the acoustic sensors of the Ly-ATOM device were located inside a possible IBL in order to detect the properties of the targeted surface (see Fig. 1). The measurements were supplemented by a net radiometer (CNR4, KIPP\& Zonen, Delft, the Netherlands), which was placed next to the Ly-ATOM. 
Table 1 Performed surface modifications during the measurement period

\begin{tabular}{ll}
\hline Type of modification & Date and time in UTC \\
\hline Irrigation & $24 / 06 / 20190930-1100$ \\
Irrigation & $25 / 06 / 20190950-1120$ \\
Dark foil & $26 / 06 / 20190830-1030$ \\
Irrigation & $27 / 06 / 20190650-0820$ \\
Irrigation & $27 / 06 / 20190900-1030$ \\
Irrigation & $28 / 06 / 20190700-0930$ \\
Irrigation & $28 / 06 / 20191445-1615$ \\
Irrigation & $29 / 06 / 20190800-1000$ \\
Dark foil & $30 / 06 / 20191000-1140$
\end{tabular}

\subsection{Raw-Data Processing}

The 10-Hz raw data of the sonic acoustic virtual temperatures and velocity components were processed, including double coordinate rotation and a spike detection algorithm (outside \pm 6 standard deviations) via an in-house program written in Fortran 90/95.

The Ly-ATOM device provided sound transit times with a temporal resolution of $1 \mathrm{~Hz}$, which were processed with the statistical programming language R. Acoustic virtual temperatures and the horizontal velocity components were calculated as described in Sect. 2.1 for the sensors, which are facing each other and passing the centre of the ring. The Ly-ATOM set-up includes an autonomous calibration, which yields the distances between all sensor heads (see Fig. 2). These preassigned distances between the sensors of the Ly-ATOM device were improved by comparison with the sonic, which serves as the reference device for a rather high-wind-speed period in the case of temperature and a calm period in the case of the velocity components. Again, a coordinate rotation was performed in which the rotation around the $y$-axis could be omitted since no vertical velocity component was detected, and outliers were removed using a spike detection algorithm.

A block-averaging time period of $10 \mathrm{~min}$ was selected for both devices in order to enable direct comparisons.

\subsection{Adjustments for Determination of Sensible Heat Fluxes with the Flux-Variance-Similarity and Alternative-Flux-Variance Methods}

\subsubsection{Estimation of Flux-Variance-Similarity Constants}

Knowledge regarding the FVS relationship $\mathrm{f}(-\zeta)(8)$ is required to apply the FVS method. The constants $C_{1}$ and $C_{2}$ were determined using a Bayesian parameter estimation approach with 10,000 iteration steps. For both $C_{1}$ and $C_{2}$, log-normal distributions were assumed as prior distributions with a geometric mean of 1 and very small precision of 0.00001 . Data points in the near-neutral range $(-\zeta>0.02)$ and outliers were removed.

The FVS constants were estimated with $95 \%$ confidence as $C_{1}=0.822( \pm 0.04)$ (mean \pm standard error) and $C_{2}=0.015( \pm 0.008)$. The obtained relationships are displayed for unstable conditions on a log-log plot (Fig. 3). As suggested by Tillman (1972), the freeconvection approximation can be assumed to be valid for values of $-\zeta<0.05$ and simplifies (8) to (11). The FVS constant $C_{1}$ differs greatly from previously reported values, which are 


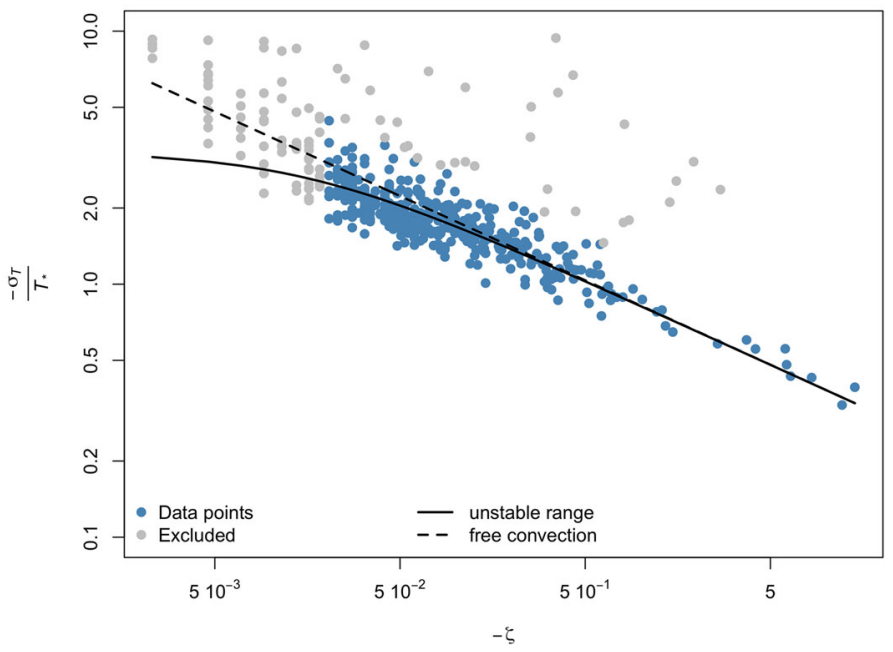

Fig. 3 Dimensionless standard deviation of air temperature as a function of $\zeta$ determined with the sonic. Data points in the near-neutral range $(\zeta<0.02)$ and outliers (outside two standard deviations of the regression line), which are represented by the grey circles, were excluded from the analysis. The solid black line represents the experimental similarity function for the whole unstable range $\sigma_{T} / T_{*}=C_{1}\left(C_{2}-\zeta\right)^{-1 / 3}$ with $C_{1}=0.822$ and $C_{2}=0.015$. The dashed black line denotes the free-convection approximation

usually in the range between 0.9 and 1.1 (Wyngaard et al. 1971; Tillman 1972; Albertson et al. 1995; Cava et al. 2008; Zhao et al. 2010), which illustrates the importance of determining the FVS relationships for each study area. The large scatter in the data is typical for measurements in the surface layer (Zahn et al. 2016). Deviations from the relationships of Wyngaard et al. (1971) and Tillman (1972) may be attributed to the heterogeneity of sources and sinks inside the surface layer, violating the assumptions of MOST (Filho et al. 2008; Zahn et al. 2016).

\subsubsection{Determination of the Correction Coefficient for the Alternative-Flux-Variance Method}

To determine the magnitude of $Q_{\mathrm{H}}$ during stable conditions, the AFV method is applied, and the constants $C_{u}$ and $C_{T}$ need to be estimated (16b). Therefore, the dimensionless standard deviations of temperature and the streamwise velocity component according to (14) and (13), respectively, are considered in terms of their dependence on the stability parameter $\zeta$ (see Fig. 4 including regression analyses). The influence of the magnitude of $\zeta$ is found to be not significant, with the constants determined to be $C_{T}=\mathrm{e}^{1.029}=2.797( \pm 0.2)$ and $C_{u}=\mathrm{e}^{0.865}=2.376( \pm 0.2)$, which agree well with the values of 3.0 and 2.3 , respectively, found by Pahlow et al. (2001). Thus, the correction coefficient for (16b) results in $r_{\text {corr }}=$ $1 /\left(C_{u} C_{T}\right)=0.15( \pm 0.06)$.

In contrast to the EC method, the applications of the FVS and AFV methods require knowledge concerning the present stratification in order to apply the correct formulae. Besides $\zeta$, this distinction can be performed with the help of the vertical temperature gradient or by consideration of the net radiation (Wesson et al. 2001; Foken 2017). Here, the distinction between stable and unstable stratification is made based on the sign of $\zeta$ and the net radiation measurements using the sonic and Ly-ATOM device, respectively. A positive net radiation 

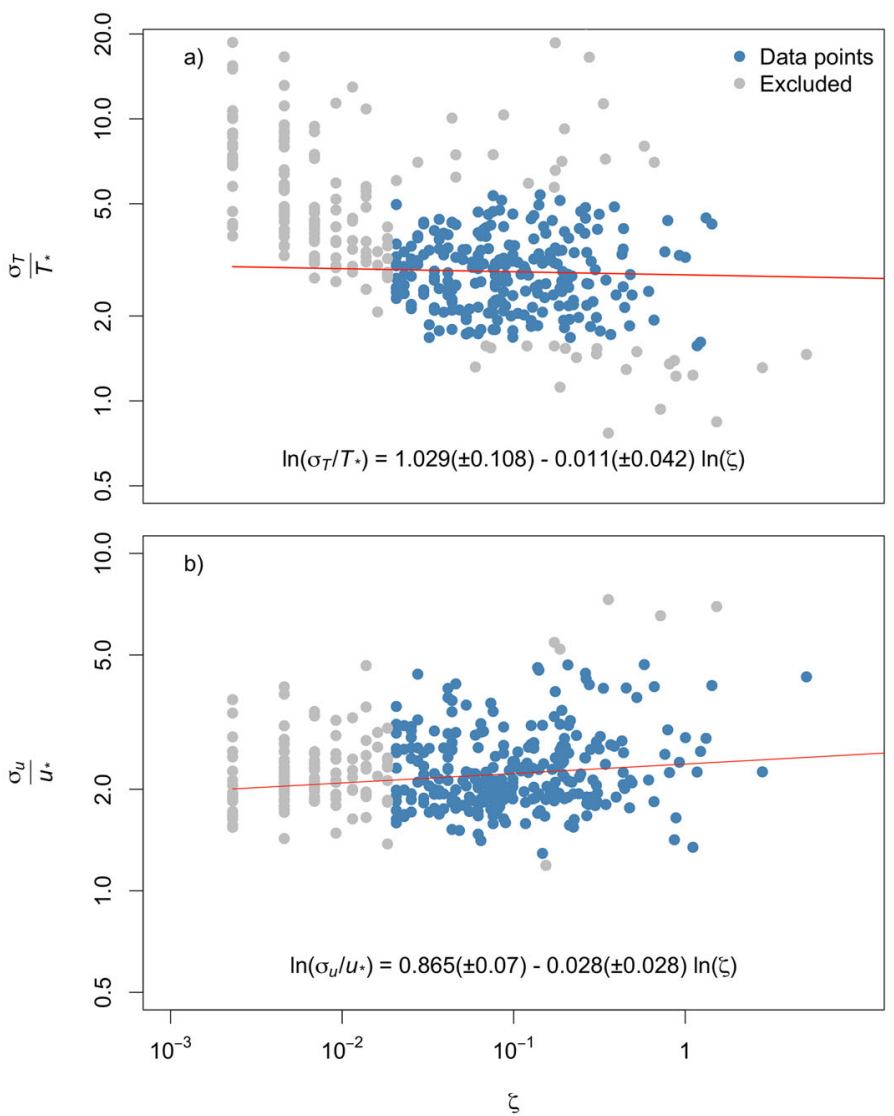

Fig. 4 Dimensionless standard deviations of air temperature (a) and the streamwise velocity component (b) as a function of $\zeta$ determined with the sonic: data points in the near-neutral range $(\zeta<0.02)$ and outliers (outside two standard deviations environment of the regression line), which are indicated by the grey circles, are excluded from the analysis. The solid red line depicts the linear-regression model

corresponds to unstable stratification, while a negative net radiation indicates stable stratification.

\subsection{Criteria for Comparison}

In order to enable comparisons between the considered time series, two criteria were employed: the index of agreement $(i A)$, which can detect additive and proportional differences in the observed and simulated means and variances, is a standardized measure of the degree of model prediction error. This parameter indicates the ratio of the mean-square error to the potential error by

$$
i A=1-\frac{\sum_{i=1}^{N}\left|O_{i}-S_{i}\right|^{2}}{\sum_{i=1}^{N}\left(\left|S_{i}-\bar{O}\right|+\left|O_{i}-\bar{O}\right|\right)^{2}},
$$


and varies between 0 and 1, where 0 indicates no match and 1 indicates a perfect agreement. Here, $O_{i}$ is the observation value, $S_{i}$ is the reference value, and $\bar{O}$ and $\bar{S}$ are the respective average values (Willmott 1981).

The root-mean-square error

$$
R M S E=\sqrt{\frac{1}{N} \sum_{i=1}^{N}\left(S_{i}-O_{i}\right)^{2}},
$$

indicates the standard deviation of the model prediction error. Since the value of RMSE is ideally zero, a large value of $R M S E$ suggests a poor agreement.

\section{Results and Discussion}

\subsection{Footprints}

Most green roofs offer only limited space and may possess obstacles, which perturb EC measurements. Since footprint models are based on the assumption of horizontal homogeneity, they can only be considered as a first approximation in complex terrain (Aubinet et al. 2012). The footprint climatologies of both measurement systems were determined using the flux-footprint model of Kljun et al. (2015) (Fig. 5). Comparing the respective 80\% footprint source area of both devices shows a remarkably larger source area of the sonic, which can be attributed to the differences in measurement height. The $80 \%$-source area of the Ly-ATOM device is reduced by about $96 \%$ compared with the sonic.

The environment cannot be considered as homogeneous and the measurements were disturbed by the surrounding allotments and walls, which were $8 \mathrm{~m}$ (to the north) and $13 \mathrm{~m}$ (to the east) away from the sonic.

\subsection{Measurements of Temperature and Velocity Components}

In Fig. 6, time series of temperature, wind direction, and wind speed recorded by the LyATOM, sonic, and LIM weather station are shown. All measurement devices detect similar values of air temperature, while wind speeds detected by the LIM weather station $(10 \mathrm{~m}$ above the ground) are significantly higher compared with the sonic and Ly-ATOM due to the logarithmic wind speed profile.

Differences between the sonic and Ly-ATOM measurements of temperature and wind speed are comparatively low ( $R M S E=0.67 \mathrm{~K}$ and $0.31 \mathrm{~m} \mathrm{~s}^{-1}$ and $i A=0.99$ and 0.84 ).

Thus, the Ly-ATOM device can reliably detect area-averaged values of temperature and wind speed in the direct vicinity of the surface.

\subsection{Sensible-Heat-Flux Estimations}

Since the Ly-ATOM device yields feasible results concerning the temperature and the velocity fluctuations, their corresponding fluctuations can be investigated in order to determine $Q_{\mathrm{H}}$ via the FVS and AFV methods. In a first step, these methods were tested with measurements of the sonic. Afterwards, the FVS and AFV methods are applied to measurements of the Ly-ATOM device. Since the EC method is the standard micrometeorological method for detecting turbulent surface heat fluxes, it serves as the reference method. 


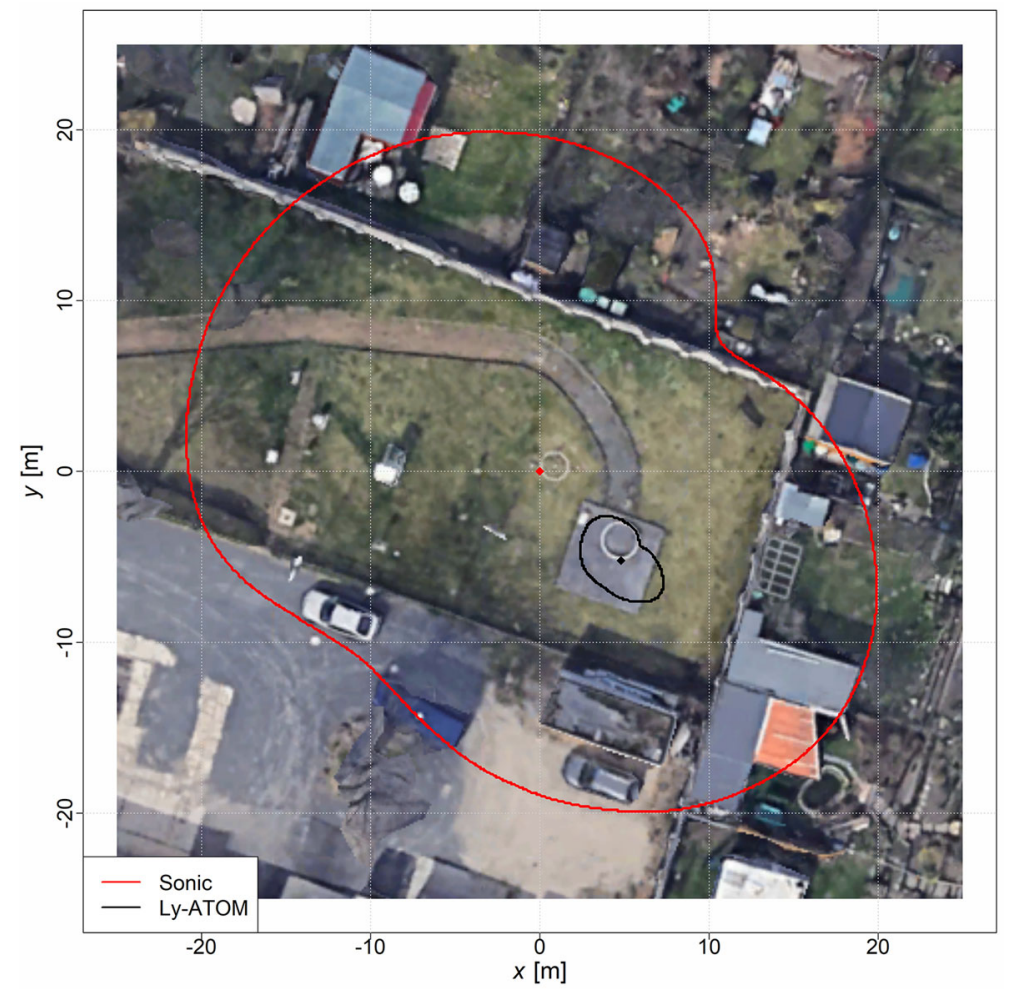

Fig. 5 Footprint climatologies of both measurement systems. The symbols denote the locations of the respective measurement device. The solid lines represent the $80 \%$ source area of the footprint climatologies according to Kljun et al. (2015)

In the case of sonic measurements, the FVS method in the near-neutral range $(0 \leq-\zeta<$ 0.05 ) was calculated according to (10), while (12) was used for $-\zeta>0.05$.

In the case of the Ly-ATOM measurements, this modification of the FVS method in the near-neutral range was not applied, since there is no information concerning the magnitude of $\zeta$ without supplementing measurements of the sonic.

\subsubsection{Sonic}

In Fig. 7, time series of $Q_{\mathrm{H}-\mathrm{EC}}$ are compared to $Q_{\mathrm{H}-\mathrm{FV}}$ and $Q_{\mathrm{H}-\mathrm{AFV}}$ for the measurement period of 24-30 June 2019. The $Q_{\mathrm{H}-\mathrm{EC}}$ follows a diurnal pattern with positive peaks around noon, which were above $200 \mathrm{~W} \mathrm{~m}^{-2}$ at each day of the measurement period, and slightly negative values around $-30 \mathrm{~W} \mathrm{~m}^{-2}$ during the night-time.

Using the FVS method, daytime $Q_{\text {H-EC }}$ values can be well reproduced during the measurement period. However, daily maximum values are slightly attenuated on 25 and 30 June.

As night-time absolute values of $Q_{\mathrm{H}}$ are quite small, the significance in an appropriate detecting was minor in past research (De Bruin and Hartogensis 2005). Nevertheless, the surface energy balance during the night-time is meaningful for urban climate research. For stable stratification, the magnitude of $Q_{\mathrm{H}-\mathrm{AFV}}$ corresponds well to that of $Q_{\mathrm{H}-\mathrm{EC}}$. 

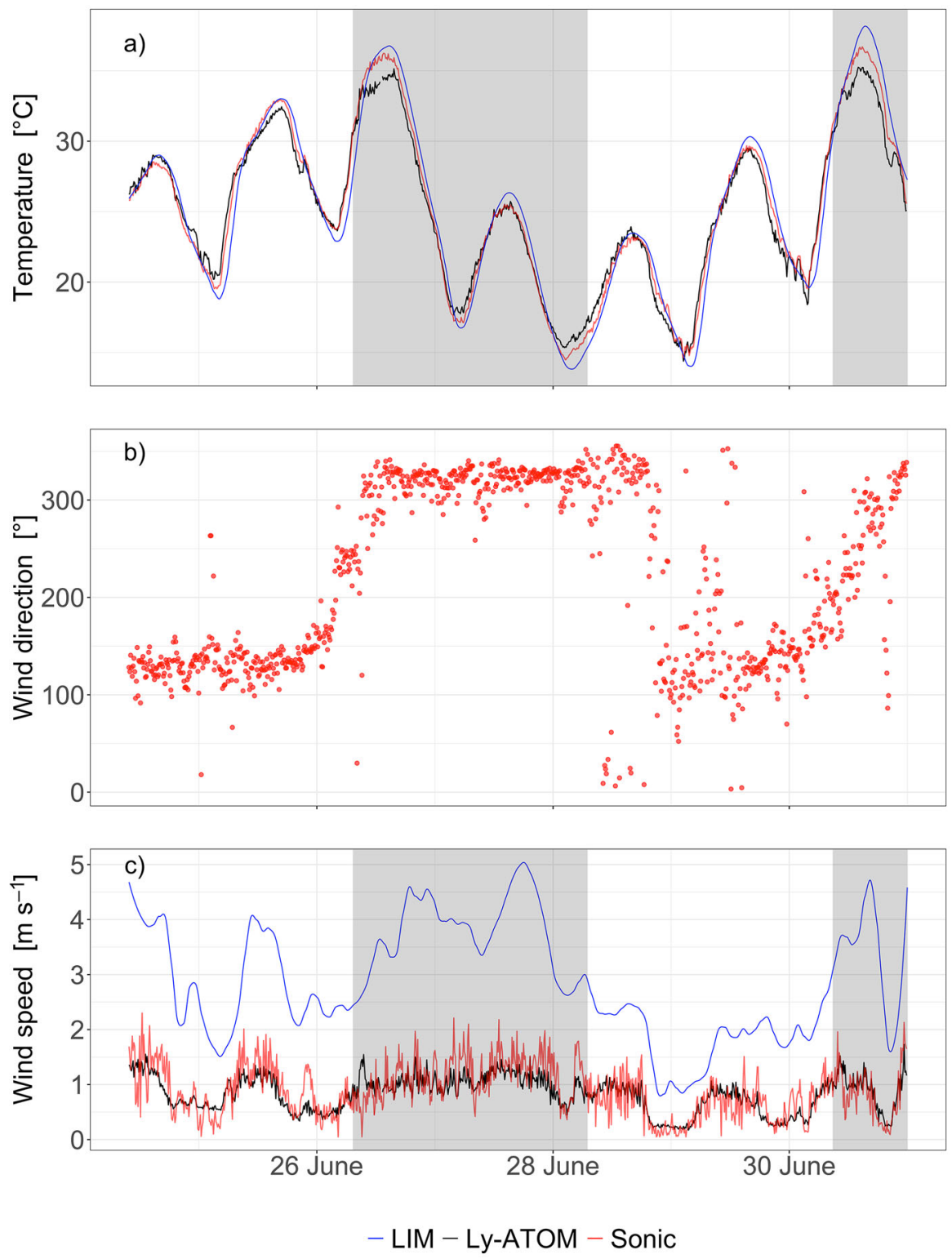

Fig. 6 Time series of $\mathbf{a}$ temperature, $\mathbf{b}$ wind direction, and $\mathbf{c}$ wind speed: The temperature and wind speed were calculated from the acoustic travel time measurements of the Ly-ATOM device $(z=0.25 \mathrm{~m})$ and measured with the sonic anemometer $(z=2.3 \mathrm{~m})$, PT100-resistance thermometer $(z=2 \mathrm{~m})$, and cup anemometer $(z=10 \mathrm{~m})$, the latter two being recorded by the LIM weather station. The grey-shaded domains indicate distorted measurements of the Ly-ATOM device due to loose sensor mountings and were, therefore, excluded from the analysis

Since a combination of the FVS and AFV methods is able to recover $Q_{\mathrm{H}-\mathrm{EC}}$ all day, these are applied to the Ly-ATOM measurements in a next step. 


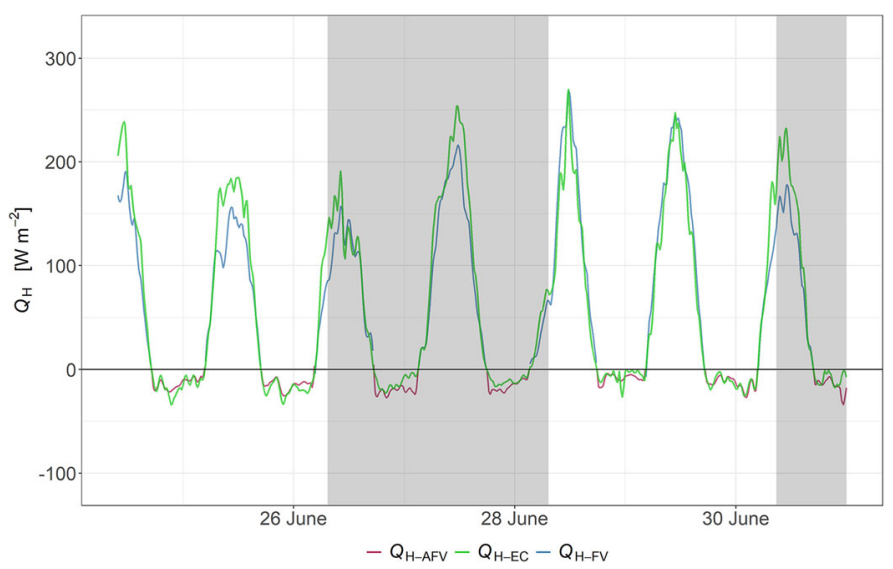

Fig. 7 Time series of $Q_{\mathrm{H}-\mathrm{FV}}, Q_{\mathrm{H}-\mathrm{AFV}}$ and $Q_{\mathrm{H}-\mathrm{EC}}$ determined with the sonic: The grey-shaded domains indicate distorted measurements of the Ly-ATOM device and were, therefore, excluded from the analysis

\subsubsection{Ly-ATOM}

The FVS and AFV methods were adopted to recordings of the Ly-ATOM device in order to measure inside the corresponding IBL of the surface. In Fig. 8, $Q_{\mathrm{H}-\mathrm{AFV}}$ and $Q_{\mathrm{H}-\mathrm{FV}}$, determined with the Ly-ATOM device, are compared to $Q_{\mathrm{H}-\mathrm{EC}}$. Again, a very good agreement with $Q_{\mathrm{H}-\mathrm{EC}}$ can be achieved using the $Q_{\mathrm{H}-\mathrm{AFV}}$ method during night-time. In contrast, daily maximums of $Q_{\mathrm{H}-\mathrm{FV}}$ are considerably reduced compared with $Q_{\mathrm{H}-\mathrm{EC}}$.

Discrepancies between the applied methods can be observed around the zero line (when the sensible heat flux changes its sign), as well, since transitions from $Q_{\mathrm{H}-\mathrm{FV}}$ to $Q_{\mathrm{H}-\mathrm{AFV}}$ (and vice versa) are less smooth compared with the sonic measurements and discontinuities are present. These may be reduced with an improved method for the differentiation between stable and unstable stratification. Moreover, differences in terms of atmospheric stratification may exist due to the differences in height and underlying surface properties. Larger deviations from the EC method are observable on 26 and 30 June, which can be attributed to the surface manipulations. These are examined in more detail in Sect.4.4.

\subsubsection{Comparison}

In order to evaluate the performance of both the AFV and FVS methods for the sonic and Ly-ATOM devices, respectively, they are compared with $Q_{\mathrm{H}-\mathrm{EC}}$ by using a Taylor diagram (Fig. 9). This comparison is not intended as a benchmarking procedure of the Ly-ATOM device against the sonic and we do not expect perfect agreement of the measured values. Instead the aim is to demonstrate that (i) the heat fluxes measured by the Ly-ATOM device are in a reasonable range, and (ii) the specific measurement conditions (sensor height, surface material, footprint area) of the Ly-ATOM device are properly reflected in the flux values. Overall, the applied methods show a reasonable agreement to the equivalent $Q_{\mathrm{H}-\mathrm{EC}}$ in terms of the standard deviation, correlation, and the magnitude of $R M S E$. For the sonic measurements, both AFV and FVS methods agree better with the EC data in terms of the magnitude of RMSE and the correlation coefficient than heat fluxes calculated from Ly-ATOM recordings. This is plausible since the $Q_{\mathrm{H}}$ values were determined with another device, above a 


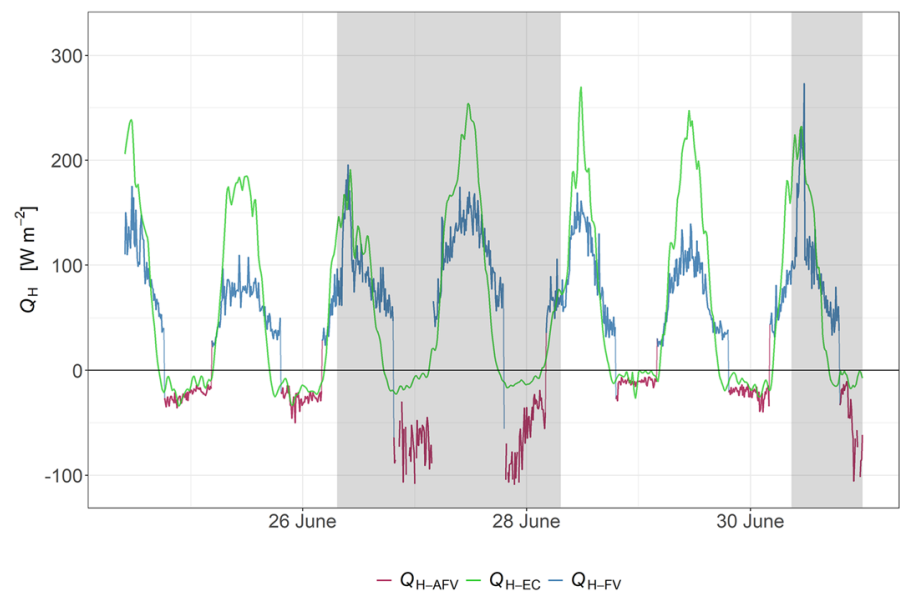

Fig. 8 Time series of $Q_{\mathrm{H}-\mathrm{AFV}}$, and $Q_{\mathrm{H}-\mathrm{FV}}$ detemined with the Ly-ATOM device compared to $Q_{\mathrm{H}-\mathrm{EC} \text {. The }}$ EC method was applied to measurements of the sonic. The differentiation between $Q_{\mathrm{H}-\mathrm{AFV}}$, and $Q_{\mathrm{H}-\mathrm{FV}}$ was performed on the basis of net radiation measurements of the CNR4 net radiometer located next to the Ly-ATOM device. The grey-shaded domains indicate distorted measurements of the Ly-ATOM device due to loose sensor mountings and were, therefore, excluded from the analysis

Table 2 Statistics for comparison of the various methods to determine $Q_{\mathrm{H}}$

\begin{tabular}{lllrl}
\hline Device & Method & Stratification & $R M S E$ in $\mathrm{W} \mathrm{m}^{-2}$ & $i A$ \\
\hline Sonic & FV & Unstable & 27.59 & 0.96 \\
& AFV & Stable & 4.62 & 0.88 \\
& Combined & & 20.15 & 0.99 \\
Ly-ATOM & FV & Unstable & 61.40 & 0.74 \\
& AFV & Stable & 9.96 & 0.68 \\
& Combined & & 48.48 & 0.88
\end{tabular}

All methods are compared with $Q_{\mathrm{H}-\mathrm{EC}}$, which was determined with the sonic anemometer at a height of $2.3 \mathrm{~m}$. The days of 26, 27, and 30 June are excluded from calculation of the statistical criteria since the measurements of the Ly-ATOM were distorted on these days

different surface, and at a different height. Corresponding numerical values for $R M S E$, and $i A$ are listed in Table 2.

The measurements with the Ly-ATOM device were conducted in the roughness sublayer, while the EC measurements were performed in the inertial sublayer. In the upper part of the surface layer, where the turbulent fluxes are almost constant with height, MOST can be generally applied (Sfyri et al. 2018). Ullah et al. (2019) found no essential differences when comparing FV measurements at different heights. Indeed, measurements of sensible heat fluxes in the roughness sublayer have not been investigated in detail. In the roughness sublayer, turbulence cannot be considered as homogeneous, wherefore MOST is not valid to its full extent and problems in flux estimations may occur (Järvi et al. 2018). This may generally account for differences of sensible heat flux estimations between sonic and LyATOM device. 


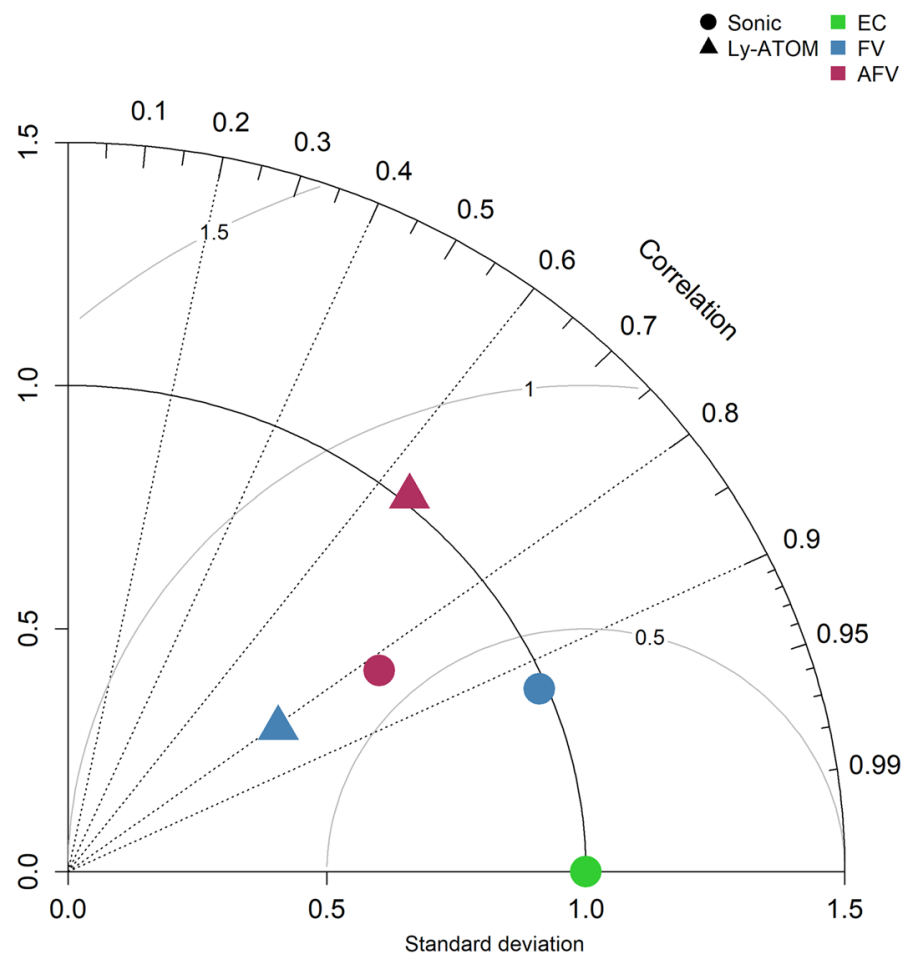

Fig. 9 Performance of different methods for the determination of $Q_{\mathrm{H}}$ in a Taylor diagram. The EC method serves as a reference for both unstable (FVS method) and stable stratification (AFV method) and is represented by the green triangle. Standard deviation (radial distance from the origin) and $R M S E$ values (represented by the concentric distances between the reference measurement and symbol) are normalized based on $Q_{\mathrm{H}-\mathrm{EC}}$. Measurements of the sonic are represented by a circle, while the triangles indicate measurements carried out with the Ly-ATOM device. The days 26, 27, and 30 June are excluded in this plot since the measurements were distorted on these days due to loose sensor mountings

\subsection{Detection of Surface Modifications}

During the measurement campaign, the surface was modified multiple times by irrigation and a dark foil. These modifications of the surface are associated with changes of temperature and $Q_{\mathrm{H}}$. It might be anticipated that watering of the surface leads to an increased latent heat flux and the sensible heat flux should be lowered since net radiation remains constant. Due to evaporation, the temperature should decrease, too. The albedo lowered by the dark foil leads to an increase in net radiation (1c), thus, the temperature and sensible heat flux increase ( $\mathrm{Li}$ et al. 2014).

Aiming to investigate the influences of the activities, the time series $Y_{t}$, was split into its respective components, trend $Y_{T, t}$, seasonality $Y_{S, t}$, and error $\epsilon_{t}$ by

$$
Y_{t}=Y_{T, t}+Y_{S, t}+\epsilon_{t}
$$

For this, a dynamic linear model, containing a diurnal seasonal component and a local level trend (second-order polynomial model), was deployed. The related Kalman filter serves as a low-pass filter for the trend (cut-off period=1 day) and as a band-pass filter for the seasonal 

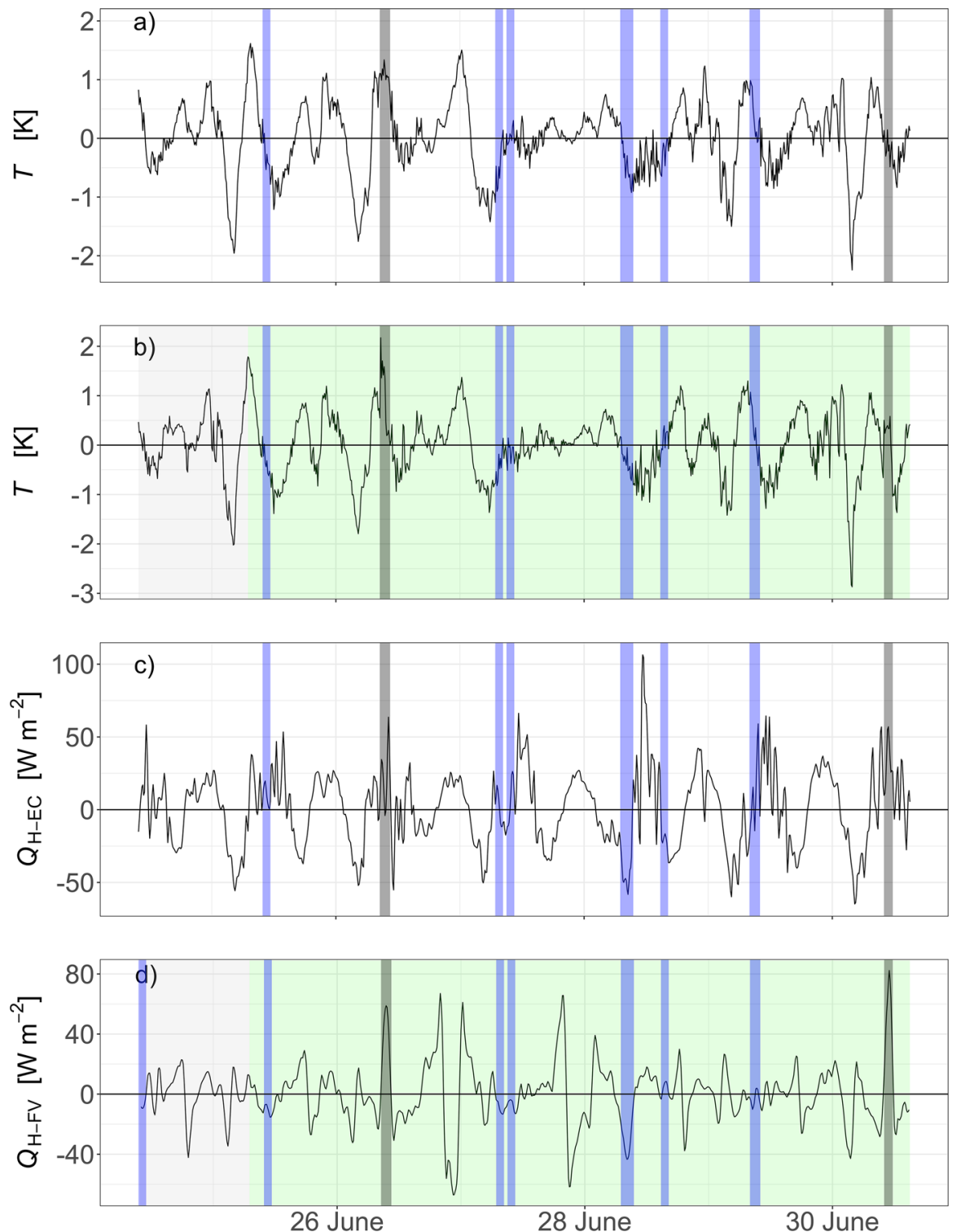

Fig. 10 Detrended and deseasonalized time series of temperatures and sensible heat fluxes recorded by the sonic in (a) and (c) and by the Ly-ATOM in (b) and (d). The grey background indicates recordings above the concrete surface, while the green background marks measurements above turf. The blue stripes refer to watering of the soil and black stripes refer to a placed dark foil. Measurements of the sonic were neither performed directly above the concrete nor the turf, for which the background was kept blank

component (period $=1$ day) (Schlink et al. 1997). Finally, the random component is calculated by subtracting the trend and seasonal components from the original signal.

Subsequently, a statistical intervention analysis examines whether there is an event over time that affects the level of the observed time series in the short or long term (Rainer 
Table 3 temperature $(\mathrm{K})$ Estimated effects of surface modifications on temperature $(\mathrm{K})$ and sensible heat fluxes $\left(\mathrm{W} \mathrm{m}^{-2}\right)$ at time $t$

\begin{tabular}{lcllll}
\hline Method & \multicolumn{2}{l}{ Watering } & & \multicolumn{2}{l}{ Dark foil } \\
\cline { 2 - 3 } \cline { 5 - 6 } & Mean & effect & & Mean & effect \\
\hline$T($ Ly $)$ & 295.2 & $-0.15( \pm 0.08)$ & & 305.1 & $0.65( \pm 0.14)$ \\
$T($ Sonic $)$ & 294.8 & $-0.17( \pm 0.07)$ & & 305.2 & $0.53( \pm 0.13)$ \\
$Q_{\text {H-FV }}$ & 69.8 & $-10.45( \pm 2.32)$ & & 107.1 & $45.23( \pm 4.02)$ \\
$Q_{\text {H-EC }}$ & 110.7 & $-7.28( \pm 4.02)$ & & 168.6 & $27.82( \pm 6.44)$ \\
\hline
\end{tabular}

Mean values correspond to the averaged level of the respective time series before the surface modification $\left(Y_{t}\right)$ and give perspective on the magnitude of the effect, while the effects correspond to the regression coefficient $b$ (with $95 \%$ confidence) in (21)

Schlittgen 2012). Therefore, a dummy variable $I_{t}$ is generated, which encodes the intervention periods of the respective surface modifications $t_{0}$ by

$$
I_{t}= \begin{cases}0 & \text { if } t \neq t_{0} \\ 1 & \text { if } t=t_{0} .\end{cases}
$$

The influence of the modifications can be evaluated using a linear-regression analysis, which was applied to the intervention model,

$$
\epsilon_{t}=b I_{t},
$$

where $b$ describes how the activity at time $t_{0}$ affects the time series.

The influence of the activities on the random components of temperatures as well as $Q_{\mathrm{H}}$ measured with both devices is depicted in Fig. 10. In Table 3, the parameters of the intervention analysis are summarized. Watering of the surface led to a decrease of the temperatures of the Ly-ATOM device and the sonic by $0.15 \mathrm{~K}$ and $0.17 \mathrm{~K}$, respectively. The dark foil increased the temperature by $0.65 \mathrm{~K}$ (Ly-ATOM) and $0.53 \mathrm{~K}$ (sonic).

Considering the sensible heat fluxes, irrigation of the surface led to a reduction of sensible heat fluxes (see minima in $Q_{\mathrm{H}}$ during blue stripes in lowermost plot of Fig. 10). For $Q_{\mathrm{H}-\mathrm{EC}}$, the effect is least pronounced and is most uncertain. The dark foil leads to an increase in the magnitude of $Q_{\mathrm{H}}$ (see peaks in $Q_{\mathrm{H}}$ during grey stripes in the lowermost plot of Fig. 10), which is much more pronounced for $Q_{\mathrm{H}-\mathrm{AFV}}$ and $Q_{\mathrm{H}-\mathrm{FV}}$ compared with $Q_{\mathrm{H}-\mathrm{EC}}$.

All in all, the conducted modifications fulfilled prior expectations. The determined effects of irrigation and the dark foil are more pronounced for the sensible heat fluxes compared with the temperature due to the extremely sensitive character of the turbulent heat fluxes (Raabe et al. 2002). Due to the underestimation of $Q_{\mathrm{H}-\mathrm{FV}}$ with the Ly-ATOM device, intervention effects of $Q_{\mathrm{H}-\mathrm{FV}}$ are minor compared with $Q_{\mathrm{H}-\mathrm{AFV}}$. For irrigation periods, however, the air humidity rises and the approximation $T \approx T_{\mathrm{av}}$ for determination of temperature, and $Q_{\mathrm{H}}$ becomes more imprecise (Schotanus et al. 1983). Since the sonic is situated outside the IBL, while the Ly-ATOM device detects surface characteristics inside the IBL, intervention analysis result in more pronounced effects for sensible heat fluxes of the Ly-ATOM device compared with the sonic. Therefore, it could be demonstrated that the Ly-ATOM device is able to detect changes in surface characteristics, and is most suitable for investigating surfaces with rather restricted spatial dimensions. At this point, it should be noted that the precise estimation of the magnitude by the respective effects is not the aim of this analysis. 


\section{Conclusions}

This work compared different approaches (EC, FVS, AFV techniques) to determine the sensible heat flux above green roofs. Besides a three-dimensional sonic anemometer, a measurement system consisting of four horizontally arranged acoustic sensors (Ly-ATOM) was utilized.

Considering the sonic measurements, AFV and FVS methods were tested and a combination of both methods result in good agreement with the EC method. Sonic measurements are not appropriate for detecting the surface energy balance of surfaces with rather restricted spatial dimensions, as it is usually the case for green roofs, since the source area of the EC method (sonic) is too large.

Therefore, with the help of the Ly-ATOM device, acoustic measurements in the proximity of the surface were employed. Thus, the corresponding footprint could be significantly decreased and the impact of obstacles on the measurements were reduced in comparison to an EC measurement set-up. It was demonstrated that the Ly-ATOM device is able to detect reliably the temperature and horizontal velocity components. The vertical velocity component cannot be measured with the Ly-ATOM device, wherefore the EC method cannot be employed. Hence, a combination of the FVS and AFV methods was applied to the Ly-ATOM measurements and compared to the eddy-covariance measurements of the sonic. Despite distinctly lower daytime $Q_{\mathrm{H}-\mathrm{FV}}$ values, the estimated heat fluxes of the Ly-ATOM device were generally still consistent with the EC measurements.

Adjustments regarding the applicability of the FVS and AFV methods, in particular the FVS constants $C_{1}$ and $C_{2}$ as well as the correction coefficient $r_{\text {corr }}$, were derived on the basis of the sonic measurements. The validity of adopting these findings to the Ly-ATOM device is questionable. Nevertheless, it could be proven that a horizontal acoustic anemometer is able to determine the sensible heat flux of the underlying and very near surface, as could be demonstrated by the greater effects of the surface modifications on the Ly-ATOM measurements compared with those of the sonic.

By combining the Ly-ATOM device with ground-heat-flux sensors, lysimeters and radiation balance measurements, all components of the energy balance can be measured. Since each measurement device detects only a small source area, statements concerning the energy balance of a particular location are enabled. Thus, comparisons between various green-roof types regarding their cooling potential on the overlying air layers are possible. In this regard, based on the evaluation of the surface modifications, this study shows a more rapid and more pronounced response on differences in surface properties of the sensible heat flux than temperature. Thus, differences between various surfaces with different surface properties regarding the impact on the overlying air can be reliably observed by the Ly-ATOM technique.

By reason of a reduced sampling frequency of the Ly-ATOM technique, spectral losses in the high-frequency range occur. Furthermore, the block averaging time span was assumed to be $10 \mathrm{~min}$, for which losses in the low-frequency range may appear as well. In order to minimize the residuals of the energy balance closure, these spectral corrections should be included in subsequent studies.

Acknowledgements This work was partly supported by the project KlimaKonform (FKZ: 01LR2005D) of the German Federal Ministry of Education and Research (BMBF).

Funding Open Access funding enabled and organized by Projekt DEAL.

Open Access This article is licensed under a Creative Commons Attribution 4.0 International License, which permits use, sharing, adaptation, distribution and reproduction in any medium or format, as long as you give 
appropriate credit to the original author(s) and the source, provide a link to the Creative Commons licence, and indicate if changes were made. The images or other third party material in this article are included in the article's Creative Commons licence, unless indicated otherwise in a credit line to the material. If material is not included in the article's Creative Commons licence and your intended use is not permitted by statutory regulation or exceeds the permitted use, you will need to obtain permission directly from the copyright holder. To view a copy of this licence, visit http://creativecommons.org/licenses/by/4.0/.

\section{References}

Albertson JD, Parlange MB, Katul GG, Chu CR, Stricker H, Tyler S (1995) Sensible heat flux from arid regions: a simple flux-variance method. Water Resour Res 31(4):969-973. https://doi.org/10.1029/94WR02978

Aubinet M, Vesala T, Papale D (2012) Eddy covariance: a practical guide to measurement and data analysis. Springer, Berlin

Ayata T, Tabares-Velasco PC, Srebric J (2011) An investigation of sensible heat fluxes at a green roof in a laboratory setup. Build Environ 46(9):1851-1861. https://doi.org/10.1016/j.buildenv.2011.03.006

Babić N, Večenaj Ž, De Wekker SFJ (2016) Flux-variance similarity in complex terrain and its sensitivity to different methods of treating non-stationarity. Boundary-Layer Meteorol 159(1):123-145. https://doi. org/10.1007/s10546-015-0110-0

Barth M, Raabe A (2011) Acoustic tomographic imaging of temperature and flow fields in air. Meas Sci Technol 22(035):102. https://doi.org/10.1088/0957-0233/22/3/035102

Barth M, Fischer G, Raabe A, Ziemann A, Weiße F (2013) Remote sensing of temperature and wind using acoustic travel-time measurements. Meteorol Z 22(2):103-109. https://doi.org/10.1127/09412948/2013/0385

Berardi U, GhaffarianHoseini A, GhaffarianHoseini A (2014) State-of-the-art analysis of the environmental benefits of green roofs. Appl Energy 115:411-428. https://doi.org/10.1016/j.apenergy.2013.10.047

Bevilacqua P, Mazzeo D, Bruno R, Arcuri N (2017) Surface temperature analysis of an extensive green roof for the mitigation of urban heat island in southern Mediterranean climate. Energy Buil 150:318-327. https://doi.org/10.1016/j.enbuild.2017.05.081

Blanusa T, Vaz Monteiro MM, Fantozzi F, Vysini E, Li Y, Cameron RW (2013) Alternatives to sedum on green roofs: can broad leaf perennial plants offer better cooling service? Build Environ 59:99-106. https://doi. org/10.1016/j.buildenv.2012.08.011

Cava D, Katul GG, Sempreviva AM, Giostra U, Scrimieri A (2008) On the anomalous behaviour of scalar flux variance similarity functions within the canopy sub-layer of a dense alpine forest. Boundary-Layer Meteorol 128(1):33. https://doi.org/10.1007/s10546-008-9276-z

Chen H, Ooka R, Huang H, Tsuchiya T (2009) Study on mitigation measures for outdoor thermal environment on present urban blocks in Tokyo using coupled simulation. Build Environ 44(11):2290-2299. https:// doi.org/10.1016/j.buildenv.2009.03.012

De Bruin HAR, Hartogensis OK (2005) Variance method to determine turbulent fluxes of momentum and sensible heat in the stable atmospheric surface layer. Boundary-Layer Meteorol 116(2):385-392. https:// doi.org/10.1007/s10546-004-1986-2

Filho EM, Sá L, Karam H, Sörgel M, Alvalá R, Souza A, Pereira M (2008) Atmospheric surface layer characteristics of turbulence above the Pantanal wetland regarding the similarity theory. Agric For Meteorol 148(6):883-892. https://doi.org/10.1016/j.agrformet.2007.12.004

Foken T (2008) Angewandte Meteorologie - Mikrometeorologische Methoden. Springer, Heidelberg. https:// doi.org/10.1007/978-3-540-74666-9_6

Foken T (2017) Micrometeorology. Springer, Heidelberg

Heusinger J, Weber S (2015) Comparative microclimate and dewfall measurements at an urban green roof versus bitumen roof. Build Environ 92:713-723. https://doi.org/10.1016/j.buildenv.2015.06.002

Heusinger J, Weber S (2016) Surface energy balance of an extensive green roof as quantified by full year eddycovariance measurements. Sci Tot Environ 577:32. https://doi.org/10.1016/j.scitotenv.2016.10.168

Heusinger J, Sailor D, Weber S (2018) Modeling the reduction of urban excess heat by green roofs with respect to different irrigation scenarios. Build Environ 131:17. https://doi.org/10.1016/j.buildenv.2018.01.003

Järvi L, Rannik Ü, Kokkonen TV, Kurppa M, Karppinen A, Kouznetsov RD, Rantala P, Vesala T, Wood CR (2018) Uncertainty of eddy covariance flux measurements over an urban area based on two towers. Atmos Meas Technol 11(10):5421-5438. https://doi.org/10.5194/amt-11-5421-2018

Jim C, Peng L (2012) Weather effect on thermal and energy performance of an extensive tropical green roof. Urban For Urban Green 11:73-85. https://doi.org/10.1016/j.ufug.2011.10.001

Juerges W (1924) Der Waermeübergang an einer ebenen Wand. Schriftleitung des Gesundheits-Ingenieurs 
Klein PM, Coffman R (2015) Establishment and performance of an experimental green roof under extreme climatic conditions. Sci Tot Environ 512-513:82-93. https://doi.org/10.1016/j.scitotenv.2015.01.020

Kljun N, Calanca P, Rotach MW, Schmid HP (2015) A simple two-dimensional parameterisation for Flux Footprint Prediction (FFP). Geosci Model Dev 8(11):3695-3713. https://doi.org/10.5194/gmd-8-36952015

Li D, Bou-Zeid E, Oppenheimer M (2014) The effectiveness of cool and green roofs as urban heat island mitigation strategies. Environ Res Lett 9(5):69. https://doi.org/10.1088/1748-9326/9/5/055002

MacIvor JS, Margolis L, Perotto M, Drake J (2016) Air temperature cooling by extensive green roofs in Toronto Canada. Ecol Eng 95:36-42. https://doi.org/10.1016/j.ecoleng.2016.06.050

Morakinyo TE, Dahanayake K, Ng E, Chow CL (2017) Temperature and cooling demand reduction by greenroof types in different climates and urban densities: a co-simulation parametric study. Energy Buil 145:226-237. https://doi.org/10.1016/j.enbuild.2017.03.066

Morau D, Libelle T, Garde F (2012) Performance evaluation of green roof for thermal protection of buildings In Reunion Island. Energy Procedia 14:1008-1016. https://doi.org/10.1016/j.egypro.2011.12.1047

$\mathrm{Ng} \mathrm{E}$, Chen L, Wang Y, Yuan C (2012) A study on the cooling effects of greening in a high-density city: an experience from Hong Kong. Build Environ 47:256-271. https://doi.org/10.1016/j.buildenv.2011.07. 014

Pahlow M, Parlange MB, Porté-Agel F (2001) On Monin-Obukhov similarity in the stable atmospheric boundary layer. Boundary-Layer Meteorol 99(2):225-248. https://doi.org/10.1023/A:1018909000098

Pires L, Fisch G, Gielow R, Souza L, Avelar A, Paula I, Girardi R (2015) A study of the internal boundary layer generated at the Alcântara Space Center. Am J Environ Sci 5:82-64. https://doi.org/10.5923/s.ajee. 201501.08

Raabe A (1983) On the relation between the drag coefficient and fetch above the sea in the case of off-shore wind in the near shore zone. Meteorol Z 6:978

Raabe A, Arnold K, Ziemann A (2002) Horizontal turbulent fluxes of sensible heat and horizontal homogeneity in micrometeorological experiments. J Atmos Ocean Technol 19:1225-1230

Raabe A, Bernhofer C, Reth S (2012) Akustische Kammer (AKK) fuer Lysimeter. Universitaet Leipzig, Technische Universitaet Dresden, Umwelt Geraete Technik GmbH, Technical report

Rainer Schlittgen (2012) Angewandte Zeitreihenanalyse mit R. Oldenbourg Verlag

Rosenzweig C, Solecki W, Parshall L, Gaffin S, Lynn B, Goldberg R, Cox J, Hodges S (2006) Mitigating New York City's heat island with urban forestry, living roofs, and light sufaces. New York City Regional Heat Island Initiative

Santamouris M (2014) Cooling the cities-a review of reflective and green roof mitigation technologies to fight heat island and improve comfort in urban environments. Sol Energy 103:682-703. https://doi.org/10. 1016/j.solener.2012.07.003

Schlink U, Herbarth O, Tetzlaff G (1997) A component time-series model for SO2 data: forecasting, interpretation and modification. Atmos Environ 31(9):1285-1295. https://doi.org/10.1016/S1352-2310(96)003068

Schotanus P, Nieuwstadt F, de Bruin H (1983) Temperature-measurement with a sonic anemometer and its application to heat and moisture fluxes. Boundary-Layer Meteorol 26:81-93. https://doi.org/10.1007/ BF00164332

Sfyri E, Rotach M, Stiperski I, Bosveld F, Lehner M, Obleitner F (2018) Scalar-flux similarity in the layer near the surface over mountainous terrain. Boundary-Layer Meteorol 169:23. https://doi.org/10.1007/ s10546-018-0365-3

Solcerova A, Van de Ven F, Wang M, Rijsdijk M, van de Giesen N (2016) Do green roofs cool the air? Build Environ 111:72. https://doi.org/10.1016/j.buildenv.2016.10.021

Speak A, Rothwell J, Lindley S, Smith C (2013) Reduction of the urban cooling effects of an intensive green roof due to vegetation damage. Urban Clim 3:40-55. https://doi.org/10.1016/j.uclim.2013.01.001

Takebayashi H, Moriyama M (2012) Study on surface heat budget of various pavements for urban heat island mitigation. Adv Mater Sci Eng 2012:11. https://doi.org/10.1155/2012/523051

Teemusk A, Mander Ü (2009) Greenroof potential to reduce temperature fluctuations of a roof membrane: a case study from Estonia. Build Environ 44(3):643-650. https://doi.org/10.1016/j.buildenv.2008.05.011

Tillman JE (1972) The indirect determination of stability, heat and momentum fluxes in the atmospheric boundary layer from simple scalar variables during dry unstable conditions. J Appl Meteorol 11(5):783792

Ullah I, Buttar N, Hu Y, Aleem M (2019) Height effect of air temperature measurement on sensible heat flux estimation using flux variance method. Pakistan J Agric Sci 6:97

Wang S, Zhang Y, Lü S, Liu H, Shang L (2013) Estimation of turbulent fluxes using the flux-variance method over an alpine meadow surface in the eastern Tibetan Plateau. Adv Atmos Sci 30(2):411-424. https:// doi.org/10.1007/s00376-012-2056-1 
Wesson KH, Katul G, Lai CT (2001) Sensible heat flux estimation by flux variance and half-order time derivative methods. Water Resour Res 37(9):2333-2343. https://doi.org/10.1029/2001WR900021

Willmott CJ (1981) On the validation of models. Phys Geogr 2(2):184-194. https://doi.org/10.1080/02723646. 1981.10642213

Wyngaard JC, Coté OR, Izumi Y (1971) Local free convection, similarity, and the budgets of shear stress and heat flux. J Atmos Sci 28(7):1171-1182

Zahn E, Dias NL, Araújo A, Sá LDA, Trebs I, Wolff S, Manzi A (2016) Scalar turbulent behavior in the roughness sublayer of an Amazonian forest. Atmos Chem Phys 16(17):11349-11366. https://doi.org/10. 5194/acp-16-11349-2016

Zhang G, He BJ, Dewancker BJ (2020) The maintenance of prefabricated green roofs for preserving cooling performance: a field measurement in the subtropical city of Hangzhou, China. Sustain Cities Soc 61(102):314. https://doi.org/10.1016/j.scs.2020.102314

Zhao X, Liu Y, Tanaka H, Hiyama T (2010) A comparison of flux variance and surface renewal methods with eddy covariance. IEEE J Sel Top Appl Earth Obs Remote Sens 3(3):345-350. https://doi.org/10.1109/ JSTARS.2010.2060473

Publisher's Note Springer Nature remains neutral with regard to jurisdictional claims in published maps and institutional affiliations. 